\title{
Differential enumeration of subpopulations in concentrated frozen and lyophilized cultures of Lactobacillus delbrueckii ssp. bulgaricus
}

\author{
Yuyu Shao, ${ }^{* 1}$ Zhaoxia Wang, $\dagger^{1}$ Qiuhua Bao, $†$ and Heping Zhang $\dagger^{2}$ \\ ${ }^{*}$ College of Food Engineering and Nutritional Science, Shaanxi Normal University, Xi'an, Shaanxi, China, 710119 \\ †Key Laboratory of Dairy Biotechnology and Engineering, Ministry of Education, Inner Mongolia Agricultural University, Hohhot, Inner Mongolia, \\ China, 010018
}

\section{ABSTRACT}

Differential enumeration of subpopulations in concentrated frozen and lyophilized cultures of Lactobacillus delbrueckii ssp. bulgaricus ND02 derived from 2 propagation procedures was determined. The subpopulations consisted of 3 categories (physiological states): viable cells capable of forming colonies on agar plates ( $\mathrm{VC}+$ ), viable cells incapable of forming colonies on agar plates (VC-), widely referred to as viable but nonculturable (VBNC) cells, and nonviable or dead cells (NVC). Counts of $\mathrm{VC}+$ were recorded using a conventional plate count procedure. A fluorescent vital staining procedure that discriminates between viable $(\mathrm{VC}+$ and $\mathrm{VC}-$ ) and NVC cells was used to determine the number of viable and nonviable cells. Both propagation procedures had 2 variables: in procedure $(\mathrm{P}) 1$, the propagation medium was rich in yeast extract (4.0\%) and the $\mathrm{pH}$ was maintained at 5.7; in $\mathrm{P} 2$, the medium was devoid of yeast extract and the $\mathrm{pH}$ was maintained at 5.1. The results showed that post-propagation operations - concentration of cells by centrifugation and subsequent freezing or lyophilization of cell concentrate -induced different degrees of transience from $\mathrm{VC}+$ to $\mathrm{VC}-$ states in cells derived from P1 and P2. Compared with cells derived from P2, cells from P1 were more labile to stress associated with centrifugation, freezing, and lyophilization, as revealed by differential counting.

Key words: nonculturable viable cells, differential count, Lactobacillus delbrueckii ssp. bulgaricus, starter culture technology

\section{INTRODUCTION}

Lactobacillus delbrueckii ssp. bulgaricus (L. bulgaricus) is widely used in the production of yogurt and cheese varieties as a component of starter cultures (Batista

Received March 20, 2017.

Accepted June 14, 2017.

${ }^{1}$ These authors contributed equally to this work.

${ }^{2}$ Corresponding author: hepingdd@vip.sina.com et al., 2015). In modern, large-scale, high-throughput dairy plants, concentrated frozen or lyophilized starter cultures are preferred to set large volumes of bulk starters or for direct setting of production tanks for yogurt or cheese vats. Ready-made concentrated frozen and lyophilized starters are manufactured in the specialized starter culture industry. To produce such concentrated cultures, proper selection of starter strains for robust acid production and flavor generation in the dairy product is necessary (Cruz et al., 2012, 2013). Additionally, it is important to optimize the technology to produce functionally efficient concentrated cultures. Technology for starter manufacture involves a series of operations consisting of propagation, concentration of cells, freezing or lyophilization, packaging, quality control, and proper transportation. Constant improvement in all of the operations is necessary to meet the demands of the highly competitive dairy industry.

Among various lactic acid bacteria used in starters, L. bulgaricus is extremely labile to various operations used to produce concentrated cultures (Wright and Klaenhammer, 1983a; Santos et al., 2014; Meneghel et al., 2017). Loss of viability at every stage - concentration, freezing, and lyophilization-occurs with L. bulgaricus, even when high populations are attained at the end of propagation. Various growth media and growth parameters have been use to alleviate the loss of viability and acid-producing characteristic of this Lactobacillus species. In a previous study (Shao et al., 2014), we described a procedure that yielded highly viable and functionally efficient concentrated lyophilized L. bulgaricus cultures. In that paper, we grouped the various operations in the production of concentrated starter cultures into 4 phases: propagating the culture in a fermentor to obtain high cell numbers; harvesting cells by centrifuging; preconditioning the cell concentrate by inducing heat-shock and (or) cold-shock proteins; and preserving either by deep-freezing or lyophilization. The focus of the work was to study the effects of propagation with respect to media composition and fermentation parameters, and to precondition the cell concentrate by inducing heat- or cold-shock proteins on the resil- 
ience of cell concentrates to subsequent preservation. The results indicated that both fermentation medium and preconditioning had profound positive effects on the survival and functional properties of the preserved end-product.

This research is an extension of the earlier work (Shao et al., 2014). In this investigation, we focused on exploring the effect of variable fermentation parameters on the physiological status of the harvested cells. Physiological status here relates to phenotypic expression signified by colony formation on agar media. Phenotypic expression based on colony-forming ability on agar media can be used to categorize stages in the progressive loss of viability: viable cells capable of colony formation on agar $(\mathbf{V C}+)$, viable cells incapable of colony formation on agar $(\mathbf{V C}-)$, and nonviable or dead cells (NVC). This phenomenon can be depicted as shown below:

$$
\begin{aligned}
& \mathrm{VC}+\stackrel{a}{\longrightarrow} \mathrm{NVC} \\
& \mathrm{VC}+\stackrel{b}{\rightleftarrows} \mathrm{VC}-\stackrel{a}{\longrightarrow} \mathrm{NVC},
\end{aligned}
$$

where $a$ is a nonreversible phenomenon, and $b$ is a reversible phenomenon; reversal occurs on repair of injury. The VC- cells are often referred to as viable but nonculturable (VBNC) cells, in which the cells are alive and metabolically active but they fail to grow using conventional culture methods (Su et al., 2016). In this paper, the VC- designation will be used. Salma et al. (2013) reported on such progressive loss of viability among 60 species of gram-positive and gram-negative bacteria in response to various environmental factors (Cunningham et al., 2009; Oliver, 2010; Chen et al., 2012; Pasquaroli et al., 2013; Prakash et al., 2013; Ayrapetyan et al., 2015; Ayrapetyan and Oliver, 2016). Most of the reported studies on this phenomenon are related to pathogenic bacteria; however, a few studies have used lactic acid bacteria to demonstrate the occurrence of the VC- state (Moreno et al., 2006).

The LIVE/DEAD BacLight Bacterial Viability Kit (Molecular Probes Inc., Eugene, OR) has been widely used for quantitative determination of $\mathrm{VC}-$ cells in various bacterial species (Nicolò et al., 2011; Malmo et al., 2013; Tawakoli et al., 2013; Fernandes et al., 2014). The differentiation of dead cells from viable cells by this technique is based on cell-membrane integrity. The kit has 2 fluorescent stains, the first of which is SYTO 9, a green fluorescent nucleic acid stain that stains bacteria with both intact and damaged cell membranes. The second reagent, propidium iodide (PI), can penetrate only bacteria with damaged cell membrane, staining them red (Stiefel et al., 2015). Propidium iodide, however, is capable of reducing the green fluorescence of SYTO 9.
Consequently, the green fluorescent-stained live bacteria (with intact membranes) can be distinguished from red-stained dead bacteria (having damaged cell membrane). Using a fluorescent microscope and a counting chamber, quantitative determination of live $(\mathrm{VC}+$ and VC-) and NVC subpopulations is possible.

To our knowledge, this is the first report to establish the occurrence of $\mathrm{VC}$ - state in L. bulgaricus in response to stress factors. Quantitative determination of the $\mathrm{VC}+, \mathrm{VC}-$, and NVC states of cells in culture could be determined by the combined use of conventional agar plating and a direct microscopic count (DMC) using a fluorescent vital staining procedure that distinguishes viable cells from nonviable (dead) cells. This procedure was used herein to compare the relative proportions of $\mathrm{VC}+, \mathrm{VC}-$, and NVC cells in concentrated lyophilized preparations derived from 2 propagation processes to discriminate between viable and nonviable cells, which would aid in developing efficient technology for starter culture production.

\section{MATERIALS AND METHODS}

\section{Bacteria and Culture Conditions}

Lactobacillus delbrueckii ssp. bulgaricus ND02 was obtained from the culture collection at the Key Laboratory of Dairy Biotechnology and Engineering, Inner Mongolia Agricultural University (Hohhot, Inner Mongolia, China). This strain was chosen because it is extremely sensitive to concentration by centrifugation, freezing, and lyophilization. A freeze-dried stock culture of this strain was activated by passage through sterile reconstituted 10\% nonfat dry milk (incubated at $37^{\circ} \mathrm{C}$ for $24 \mathrm{~h}$ ), followed by another transfer in sterile de Man, Rogosa, and Sharpe (MRS) broth under similar incubation conditions.

\section{Propagation in Fermentors}

Two 5-L fermentors (Eastbio, GUJS-5, Zhenjiang East Biotech Equipment and Technology Co. Ltd., Zhenjiang, China), designated F1 and F2, were installed in parallel. Fermentor F1 was designated for process $(\mathbf{P}) 1$, in which MRS broth containing $4 \%$ yeast extract was the propagation medium, and the $\mathrm{pH}$ was maintained at 5.7. In F2, designated for P2, the medium was MRS broth free of yeast extract, and the $\mathrm{pH}$ was controlled at 5.1. The 2 fermentors were separately filled with 3 $\mathrm{L}$ of sterile propagation medium (MRS broth with or without yeast extract). The initial $\mathrm{pH}$ of the medium in both fermentors was adjusted to 6.5 using $25 \% \mathrm{NH}_{4} \mathrm{OH}$ as the neutralizer. The incubation temperature for fermentors was set at $37^{\circ} \mathrm{C}$. After setting the respective 
$\mathrm{pH}$ controls for F1 and F2, the vessels were inoculated with the activated culture at a rate of $1 \%$. Cessation of neutralizer demand, as indicated by the $\mathrm{pH}$ tracing on the chart, marked the end-point for both P1 and P2.

\section{Sampling}

Samples (5-mL aliquots) were taken from F1 and F2 and analyzed separately. A portion of each sample was used for $\mathrm{VC}+$ counts by plating on MRS agar (incubated at $37^{\circ} \mathrm{C}$ for $48 \mathrm{~h}$ ); the remaining samples were used for differential vital fluorescent staining technique for determining the counts of living cells $(\mathrm{VC}+$ and $\mathrm{VC}-$ cells) and NVC. After being harvested by centrifugation $\left(5,116 \times g\right.$ for $10 \mathrm{~min}$ at $\left.4^{\circ} \mathrm{C}\right)$, the cells were washed twice in $0.8 \%$ saline. The washed cells were suspended in a cryoprotective mixture $(349.2 \mathrm{~g})$ consisting of $10 \%$ nonfat milk and $1 \%$ sodium glutamate (1:6 wt/wt). The cell concentrates from P1 and P2 were divided into 20 -g portions and frozen at $-40^{\circ} \mathrm{C}$. After $2.5 \mathrm{~h}$, each of the concentrated cell suspensions (from P1 and P2) was lyophilized over a 36 -h period. The remaining frozen samples were retained for differential enumeration in freeze-thaw experiments. The lyophilized preparations were stored at $-18^{\circ} \mathrm{C}$.

\section{Enumeration by Plate Count}

Suitable decimal dilutions of the respective fermentation broths at the end of propagation were plated by pour plate technique using MRS agar; then, dilutions were incubated at $37^{\circ} \mathrm{C}$ for $48 \mathrm{~h}$ and colonies were counted. For frozen samples, suitable decimal dilutions were plated on MRS agar after thawing, incubated at $37^{\circ} \mathrm{C}$ for $48 \mathrm{~h}$ and colonies were counted. For lyophilized powders, a 0.5-g sample was used to make serial decimal dilutions and plated, and colonies were counted as described. Plate counts for both the fermentation broths and lyophilized samples were made in triplicate.

\section{Differential Enumeration}

Samples from F1 and F2 (25 mL each) at the end of fermentation were centrifuged at $12,000 \times g$ for $10 \mathrm{~min}$ at $4^{\circ} \mathrm{C}$. The cell pellet was washed 3 times in Ringer's solution, and the washed cells were suspended in $5 \mathrm{~mL}$ of $0.85 \% \mathrm{NaCl}$. For differential counting, the LIVE/ DEAD BacLight Bacterial Viability Kit (L7012) was used according to the kit instructions. Reagents SYTO $9(3.34 \mathrm{mM})$ and PI $(20 \mathrm{mM})$ were mixed in a ratio of 1.2:1 (vol/vol) in an Eppendorf vial and stored in the dark. One microliter of the dye mixture was added to $500 \mu \mathrm{L}$ of the prepared cell suspension, mixed well, and then held in the dark at room temperature for $15 \mathrm{~min}$. After incubation, the stained cells were loaded into a microscopic cell counting chamber, and observed under a fluorescent microscope (Leica DM 4000B; Leica Microsystems Ltd., Heerbrugg. Switzerland) at a total magnification of $400 \times$. The fluorescent image was captured using the software LAS V3.7 (Leica Microsystems Ltd.). The length of the bacterial cells was measured using the subsidiary software (Leica Qwin V3). Differential counting was done in triplicate for both the fermentation broths and the lyophilized powders. For lyophilized samples, $0.5 \mathrm{~g}$ of each powder was first suspended uniformly in $25 \mathrm{~mL}$ of Ringer's solution and then the cells were centrifuged and treated in the same way as the fermentor liquor from F1 and F2.

\section{Counting Cells}

The area of the counting chamber is $1.0 \mathrm{~mm}^{2}$. Within that area, there are 25 medium-sized grids, which are subdivided into 16 smaller grids, such that there are a 400 small grids in the counting chamber. The depth of the chamber is $0.1 \mathrm{~mm}$. The sample volume loaded into the counting chamber was $0.1 \mathrm{~mm}^{3}$. Bacterial cells in 5 small grids in each of 20 microscopic fields were counted (a total of 100 small grids). Suitable dilutions of the samples were made before loading the chamber so that an accurate count could be made. The following formula was used to determine the cell count in the freeze-thaw study:

$$
\begin{aligned}
\text { Cell density } & =\frac{\text { No. of cells in } 100 \text { small grids }}{100} \\
& \times \text { sum of small grids } \times \frac{\text { dilution factor }}{\text { volume of chamber }} .
\end{aligned}
$$

\section{Freeze-Thaw Study}

Temperature fluctuations, and even freeze-thaw cycles, often occur as frozen cultures move through marketing channels. Similar fluctuations could occur because of mishandling of frozen cultures in dairy plants. Such cyclic phase transitions from frozen state to partial or complete liquid state and the reverse are detrimental to bacterial cell viability. To simulate the freeze-thaw cycles that could occur in the marketing chain, and to determine the effect of repeated freeze-thaw cycles on cell viability, samples of concentrated frozen cultures (held at $-40^{\circ} \mathrm{C}$ ) were subjected alternately to thawing at $20^{\circ} \mathrm{C}$ for $4 \mathrm{~h}$ and refreezing, holding at $-40^{\circ} \mathrm{C}$ for 20 $\mathrm{h}$, and repeating the process through several cycles. At every thaw stage, plate counts and differential counts were made. The process was repeated until no colonies 

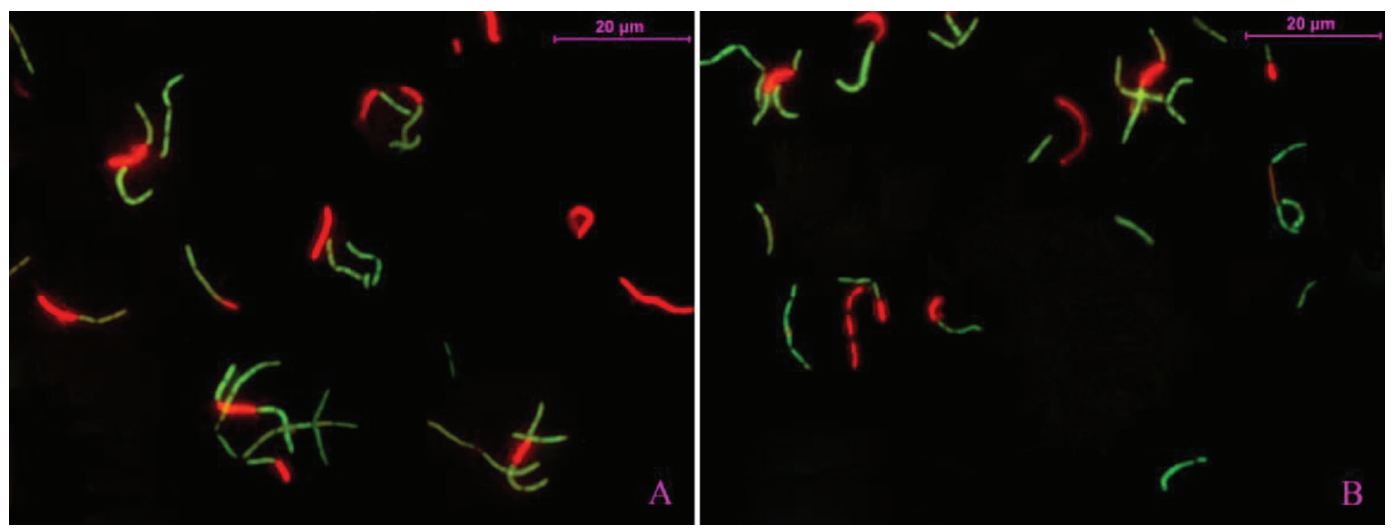

Figure 1. Fluorescent images of living (green; brighter) and dead (red; duller) bacteria in P1 fermented broth (A) and after freeze-thaw storage (B). Color version available online.

were detected on plate counts even when samples were plated directly without any dilution.

\section{Statistical Analysis}

Statistical analysis of data was performed using $\mathrm{R}$ program (v 3.3.0; https://www.r-project.org/), and significant differences between the 2 samples were evaluated by $t$-test. The experiments were done in triplicate and the results are expressed as means \pm standard deviations. Figure 2 was plotted using GraphPad Prism 5.0 (GraphPad Inc., San Diego, CA).

\section{RESULTS AND DISCUSSION}

The results of the plate and differential counts on the propagation broths from $\mathrm{F} 1$ and $\mathrm{F} 2$ and the respective bacterial cell lengths are summarized in Table 1. More living bacteria were found at the end of propagation in samples from F1 than samples from F2. In sample $\mathrm{F} 1$, plate counts showed a count of $1.06 \times 10^{10} \mathrm{cfu} / \mathrm{mL}$ $(\mathrm{VC}+)$. The count of living bacteria $(\mathrm{VC}+$ and $\mathrm{VC}-$ ) by differential DMC was $1.45 \times 10^{10}$ cells $/ \mathrm{mL}$ (Figure $1 \mathrm{~A})$, which was significantly $(P<0.05)$ greater than the plate count results. This indicates that cells in F1 had transitioned from the $\mathrm{VC}+$ to the $\mathrm{VC}-$ state. In contrast, the sample from F2 at the end of fermentation had only $4.30 \times 10^{9} \mathrm{cfu} / \mathrm{mL}$, and by $\mathrm{DMC}$, the viable cell count was $4.32 \times 10^{9}$ cells $/ \mathrm{mL}$. The difference between the plate count and the DMC was not significant $(P>0.05)$, indicating that very few or none of the cells had transitioned from the $\mathrm{VC}+$ to the $\mathrm{VC}-$ state.

The disparity in cell counts between samples F1 and F2 was large. The lower count in sample F2 could be attributed to the lack of sufficient protein and nutrients (i.e., lack of yeast extract) in the $\mathrm{F} 2$ propagation formula and the more acidic environment ( $\mathrm{pH}$ 5.1) during propagation. The growth medium in $\mathrm{F} 1$ had $4 \%$ yeast extract and $\mathrm{pH}$ control during propagation was 5.7. Whereas the culture in F1 reached the end-point (cessation of demand for neutralizer) by $6.5 \mathrm{~h}$, the culture in F2 reached the end-point after more than $11 \mathrm{~h}$.

The most important finding in the study was that the propagation conditions (medium composition and $\mathrm{pH}$ control during fermentation) had a profound effect on the colony-forming ability of the cells. Thus, the propagation conditions in $\mathrm{F} 1$ (medium with $4 \%$ yeast extract content and $\mathrm{pH}$ control at 5.7 during fermentation) predisposed the cells to a declining path in viability. The conditions in F2 yielded cells that retained the VC+ phenotype. This shows that establishing optimum conditions for propagation is of primary importance in

Table 1. Differential count of subpopulations in the fermentation broth at the end of fermentation

\begin{tabular}{|c|c|c|c|c|c|}
\hline Fermentation stream $^{1}$ & $\begin{array}{l}\text { Fermentation } \\
\text { duration }(\mathrm{h})\end{array}$ & $\begin{array}{l}\text { Cell length } \\
\quad(\mu \mathrm{m})\end{array}$ & $\begin{array}{c}\mathrm{DMC}^{2} \\
(\log \text { cells } / \mathrm{mL})\end{array}$ & $\begin{array}{l}\text { Plate count } \\
(\log \mathrm{cfu} / \mathrm{mL})\end{array}$ & $P$-value ${ }^{3}$ \\
\hline MRS (4\% yeast extract); $\mathrm{pH}=5.7$ & 6.50 & $5.00 \pm 0.18$ & $\begin{array}{l}10.16 \pm 0.013 \\
\left(1.45 \times 10^{10} \text { cells } / \mathrm{mL}\right)\end{array}$ & $\begin{array}{l}10.03 \pm 0.008 \\
\left(1.06 \times 10^{10} \mathrm{cfu} / \mathrm{mL}\right)\end{array}$ & 0.0004 \\
\hline
\end{tabular}

${ }^{1} \mathrm{MRS}=$ de Man, Rogosa, and Sharpe.

${ }^{2}$ Direct microscopic count.

${ }^{3} P$-values show the statistically significant differences between the cell counts detected by the DMC and plate count. 
Table 2. Enumeration of subpopulations in the lyophilized cultures

\begin{tabular}{lccc}
\hline Fermentation stream $^{1}$ & $\begin{array}{c}\text { Cell length } \\
(\mu \mathrm{m})\end{array}$ & $\begin{array}{c}\text { DMC }^{2} \\
(\log \text { cells/g) }\end{array}$ & $\begin{array}{c}\text { Plate count } \\
(\log \mathrm{cfu} / \mathrm{g})\end{array}$ \\
\hline MRS (4\% yeast extract); $\mathrm{pH}=5.7$ & $4.81 \pm 0.12$ & $10.65 \pm 0.028$ & $9.58 \pm 0.012$ \\
& & $\left(4.42 \times 10^{10} \mathrm{cells} / \mathrm{g}\right)$ & $\left(3.81 \times 10^{9} \mathrm{cfu} / \mathrm{g}\right)$ \\
MRS (yeast extract-free); $\mathrm{pH}=5.1$ & $2.07 \pm 0.09$ & $11.03 \pm 0.025$ & $11.00 \pm 0.006$ \\
& & $\left(1.07 \times 10^{11} \mathrm{cells} / \mathrm{g}\right)$ & $\left(1.01 \times 10^{11} \mathrm{cfu} / \mathrm{g}\right)$ \\
\hline
\end{tabular}

${ }^{1} \mathrm{MRS}=$ de Man, Rogosa, and Sharpe.

${ }^{2}$ Direct microscopic count.

${ }^{3} P$-values show the statistically significant differences between the cell counts detected by the DMC and plate count.

developing an efficient technology for production of concentrated L. bulgaricus cultures.

The deleterious effect of high concentrations of yeast extract on viability needs further study. Cogan et al. (1968) found that although tomato solids in low concentrations stimulated growth of L. bulgaricus, in high concentrations, it inhibited acid production in milk by the bacteria. Cogan et al. (1968) identified xylose and an adenine-containing nucleotide in tomato solids to be the incriminating components for inhibition. A similar nutrient toxicity might be involved in causing progressive loss of viability with high yeast extract levels in propagation medium for high-density cultures of lactobacilli. Yeast extracts are known to contain high concentrations of nucleotides (Peppler, 1982).

Another variation noted between cells from $\mathrm{F} 1$ and F2 was the difference in cell dimensions. Cells from F1 $(5.00 \mu \mathrm{m})$ were twice as long as those from F2 $(2.40 \mu \mathrm{m})$. This confirmed our previous observations (Shao et al., 2014). Wright and Klaenhammer (1983a), working with L. bulgaricus 1243, examined the effect of $\mathrm{Ca}^{2+}$ ions and environmental $\mathrm{pH}$ on the cell morphology of this bacterium. In the presence of $\mathrm{Ca}^{2+}$ and an environmental $\mathrm{pH}$ of $\leq 6.0$, cells of $L$. bulgaricus 1243 existed as short rods. At $\mathrm{pH} 7.0$, even in the presence of $\mathrm{Ca}^{2+}$, the cells assumed a long filamentous morphology. The filaments consisted of cells in chains, which failed to separate into individual units. Further, the cells in filaments displayed spherical protrusions of the cell membrane at discrete intervals on the cell surface. Wright and Klaenhammer (1983a) proposed that the elongated cell structure and distorted cell membrane protrusions could render the cells sensitive to freezing. In general among lactobacilli, it has been observed that the shorter the cell, the better their cryo-stability (Wright and Klaenhammer, 1983b).

The data for lyophilized concentrated cultures are shown in Table 2. Following freeze-drying, only 8.7\% of the population from the F1 stream were recovered on agar plating $(\mathrm{VC}+)$. In the $\mathrm{F} 1$ freeze-dried powder, DMC revealed that viable cells totaled $23.7 \%$ of the population. This means that the $\mathrm{VC}-$ phenotype ac- counted for more than $60 \%$ of the total viable count $(\mathrm{VC}+$ and $\mathrm{VC}-$ ) as recorded by DMC. At the end of propagation in $\mathrm{F} 1$, a large proportion of the cells had transitioned to the $\mathrm{VC}$ - state. A further attrition of $\mathrm{VC}+$ cells during the freeze-drying process to the $\mathrm{VC}-$ phenotype and concomitant loss of viability resulted in a very low plate count for sample $\mathrm{F} 1$ (only $8.7 \%$ of the population). The viable count of $\mathrm{F} 2$ powder as determined by plate count $(\mathrm{VC}+)$ did not significantly $(P>0.05)$ differ from counting by the vital fluorescent stain method, indicating that very little or no loss in viability occurred in that sample. This again points to the importance of optimizing initial propagation of cells to ensure maximum viability of $L$. bulgaricus cultures through preservative processes such as concentration and freezing (and sale as frozen cells) or as lyophilized powder.

Although the F2 fermentation yielded cells that were stable through centrifugation and lyophilization, the initial cell population was relatively low at the end of propagation. The absence of yeast extract, a known stimulant of bacterial growth, probably explains the low cell numbers. This could be remedied by using other stimulatory ingredients such as corn steep solids, malt extract, or tomato solids in limited amounts (Cogan et al., 1968). Further research in this area is necessary.

As mentioned earlier, freeze-thaw experiments were conducted to simulate extreme conditions that frozen cultures could undergo through marketing channels and at the site of application. In these trials, the viable counts as determined by plate counts declined steadily for both F1 and F2 frozen concentrates (Figure 2). It took $8 \mathrm{~d}$ for $\mathrm{F} 1$ concentrate to reach the targeted end-point, where no colonies were seen, even in direct plating of the concentrate (i.e., without dilution). However, at that stage, a small number of "live" cells (VC-; $3.10 \times 10^{3}$ cells) were detected by the vital staining technique (Figure 1B). The concentrate from the F2 stream took $12 \mathrm{~d}$ to reach the end-point. There were $<100$ "live" cells in the F2 sample at that stage by the vital staining technique. In this stress test, cells derived from the F2 stream showed greater resilience. 


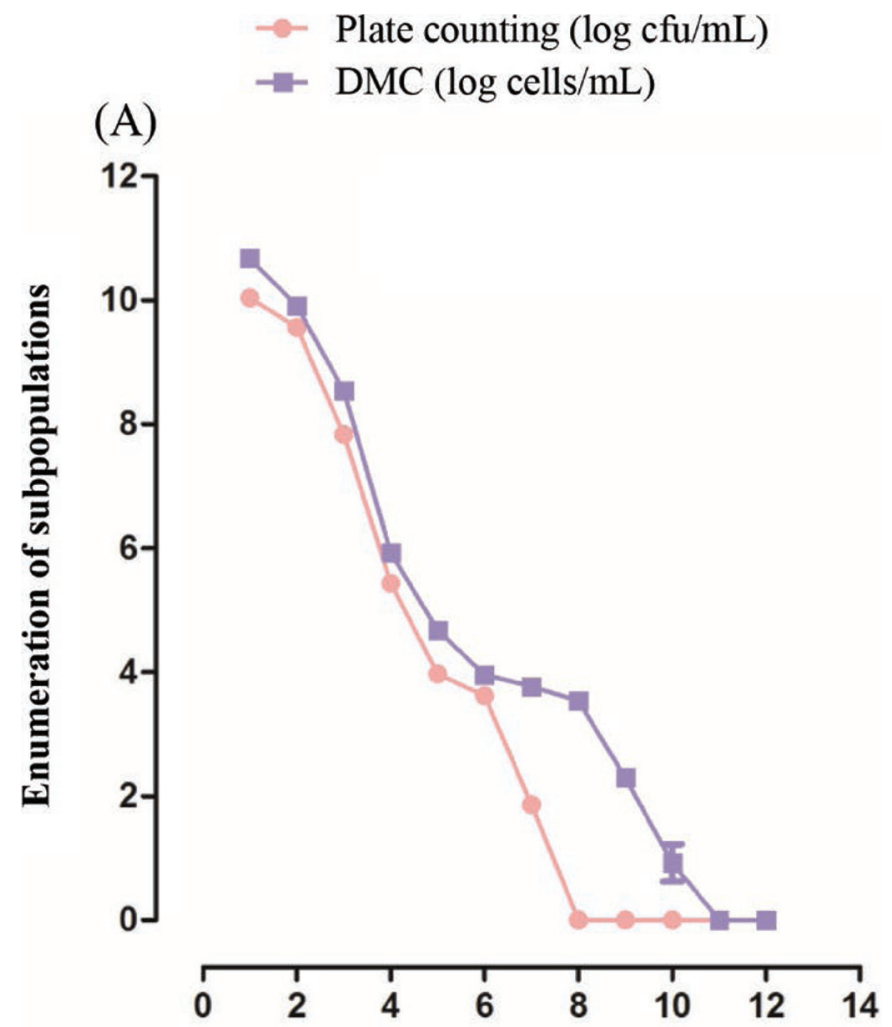

(B)

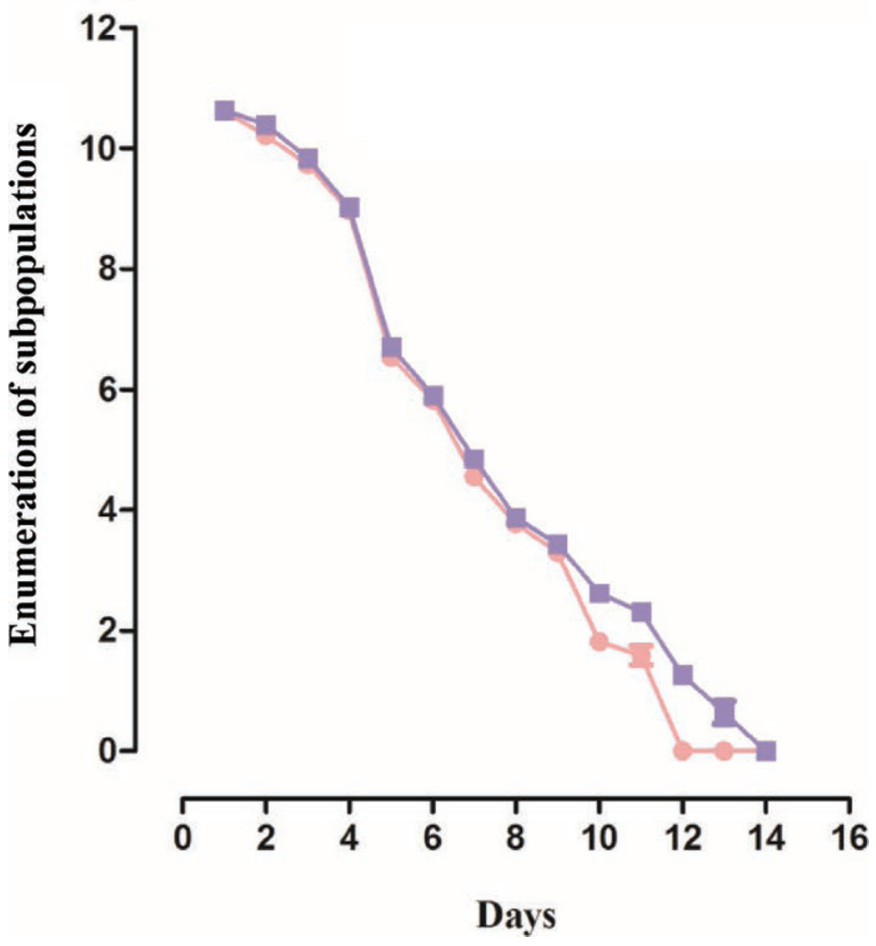

Figure 2. Changes in subpopulations of the concentrated frozen cultures sampled from (A) fermentor F1 and (B) fermentor F2 during the freeze-thaw process. $\mathrm{DMC}=$ direct microscopic count. Color version available online.
In industrial-scale starter culture production, starter bacteria undergo greater stress when fermentation stream is directed through "desludging" centrifuges. Within such centrifuges, the temperature of the fermentation stream can reach as high as $30^{\circ} \mathrm{C}$. The cell concentrate discharged from the centrifuge needs to be cooled rapidly to prevent cell damage. In membrane separation or ceramic ultrafiltration, bacterial cells are subjected to shear forces. In large-scale freeze-drying, cell concentrates frozen in large pans as sheets $(>1-2$ $\mathrm{cm}$ in thickness) are loaded onto shelves in industrial lyophilizers. To aid efficient sublimation, controlled heat is applied to the shelves in contact with the pans bearing the frozen sheet of cell concentrate. All of these factors affect cell viability, which should be taken into account in developing a suitable technology for production of starter cultures on an industrial scale. In this paper, we present evidence to show that differential counting, using plate counts and direct microscopic differential counting using vital fluorescent staining, would aid in developing efficient technology for starter culture production. This procedure could be adapted for other industrially important food and dairy bacteria, which are difficult to concentrate and preserve by freezing or freeze-drying. Examples include probiotic Lactobacillus spp. and other lactobacilli.

\section{ACKNOWLEDGMENTS}

This research was supported by the National Natural Science Foundation of China (Beijing, China; no. 31430066 and no. 31301516), the Fundamental Research Funds for the Central Universities (grant no. GK201603097), and the Science and Technology Research and Development Program of Shaanxi Province, China (No. 2016NY-207). The authors thank Ebenezer R. Vedamuthu (retired, Quest International, Rochester, $\mathrm{MN}$ ) for assistance in the preparation of this paper.

\section{REFERENCES}

Ayrapetyan, M., and J. D. Oliver. 2016. The viable but non-culturable state and its relevance in food safety. Curr Opin. Food Sci. 8:127-133.

Ayrapetyan, M., T. C. Williams, and J. D. Oliver. 2015. Bridging the gap between viable but non-culturable and antibiotic persistent bacteria. Trends Microbiol. 23:7-13.

Batista, A. L. D., R. Silva, L. P. Cappato, C. N. Almada, R. K. A. Garcia, M. C. Silva, R. S. L. Raices, D. B. Arellano, A. S. Sant'Ana, C. A. C. Junior, M. Q. Freitas, and A. G. Cruz. 2015. Quality parameters of probiotic yogurt added to glucose oxidase compared to commercial products through microbiological, physical-chemical and metabolic activity analyses. Food Res. Int. 77:627-635.

Chen, H., L. Fu, L. Luo, J. Lu, W. L. White, and Z. Hu. 2012. Induction and resuscitation of the viable but nonculturable state in a cyanobacteria-lysing bacterium isolated from cyanobacterial bloom. Microb. Ecol. 63:64-73. 
Cogan, T. M., S. E. Gilliland, and M. L. Speck. 1968. Characterization of an inhibitor for Lactobacillus bulgaricus in tomato juice. Appl. Microbiol. 16:1220-1224.

Cruz, A. G., W. F. Castro, J. A. F. Faria, H. M. A. Bolini, R. M. S Celeghini, R. S. L. Raices, C. A. F. Oliveira, M. Q. Freitas, C. A. Conte Júnior, and E. T. Mársico. 2013. Stability of probiotic yogurt added with glucose oxidase in plastic materials with different permeability oxygen rates during the refrigerated storage. Food Res. Int. 51:723-728.

Cruz, A. G., W. F. Castro, J. A. F. Faria, P. C. B. Lollo, J. AmayaFarfán, M. Q. Freitas, D. Rodrigues, C. A. F. Oliveira, and H. T. Godoy. 2012. Probiotic yogurts manufactured with increased glucose oxidase levels: Postacidification, proteolytic patterns, survival of probiotic microorganisms, production of organic acid and aroma compounds. J. Dairy Sci. 95:2261-2269.

Cunningham, E., C. O'Byrne, and J. D. Oliver. 2009. Effect of weak acids on Listeria monocytogenes survival: Evidence for a viable but nonculturable state in response to low pH. Food Contr. 20:11411144.

Fernandes, E., V. C. Martins, C. Nóbrega, C. M. Carvalho, F. A. Cardoso, S. Cardoso, J. Dias, D. Deng, L. D. Kluskens, P. P. Freitas, and J. Azeredo. 2014. A bacteriophage detection tool for viability assessment of Salmonella cells. Biosens. Bioelectron. 52:239-246.

Malmo, C., A. La Storia, and G. Mauriello. 2013. Microencapsulation of Lactobacillus reuteri DSM 17938 cells coated in alginate beads with chitosan by spray drying to use as a probiotic cell in a chocolate soufflé. Food Bioproc. Techol. 6:795-805.

Meneghel, J., S. Passot, S. Dupont, and F. Fonseca. 2017. Biophysical characterization of the Lactobacillus delbrueckii ssp. bulgaricus membrane during cold and osmotic stress and its relevance for cryopreservation. Appl. Microbiol. Biotechnol. 101:1427-1441.

Moreno, Y., M. C. Collado, M. A. Ferrús, J. M. Cobo, E. Hernández, and M. Hernández. 2006. Viability assessment of lactic acid bacteria in commercial dairy products stored at $4{ }^{\circ} \mathrm{C}$ using LIVE/ DEAD $^{\boxplus}$ BacLight ${ }^{\mathrm{TM}}$ staining and conventional plate counts. Int. J. Food Sci. Technol. 41:275-280.

Nicolò, M. S., A. Gioffrè, S. Carnazza, G. Platania, I. D. Silvestro, and S. P. Guglielmino. 2011. Viable but nonculturable state of foodborne pathogens in grapefruit juice: A study of laboratory. Foodborne Pathog. Dis. 8:11-17.
Oliver, J. D. 2010. Recent findings on the viable but nonculturable state in pathogenic bacteria. FEMS Microbiol. Rev. 34:415-425.

Pasquaroli, S., G. Zandri, C. Vignaroli, C. Vuorro, G. Donelli, and F. Biavasco. 2013. Antibiotic pressure can induce the viable but non-culturable state in Staphylococcus aureus growing in biofilms. J. Antimicrob. Chemother. 68:1812-1817.

Peppler, H. J. 1982. Yeast extracts. Pages 293-311 in Fermented Foods. Economic Microbiology. Vol. 7. A. H. Rose, ed. Academic Press, London, UK.

Prakash, O., Y. Nimonkar, and Y. S. Shouche. 2013. Practice and prospects of microbial preservation. FEMS Microbiol. Lett. 339:1-9.

Salma, M., S. Rousseaux, A. S. Grand, B. Divol, and H. Alexandre. 2013. Characterization of the viable but nonculturable (VBNC) state in Saccharomyces cerevisiae. PLoS One 8:e77600.

Santos, M. I., E. Gerbino, C. Araujo-Andrade, E. E. Tymczyszyn, and A. Gómez-Zavaglia. 2014. Stability of freeze-dried Lactobacillus delbrueckii ssp. bulgaricus in the presence of galacto-oligosaccharides and lactulose as determined by near infrared spectroscopy. Food Res. Int. 59:53-60.

Shao, Y., S. Gao, H. Guo, and H. Zhang. 2014. Influence of culture conditions and preconditioning on survival of Lactobacillus delbrueckii subspecies bulgaricus NDO2 during lyophilization. J. Dairy Sci. 97:1270-1280.

Stiefel, P., S. Schmidt-Emrich, K. Maniura-Weber, and Q. Ren. 2015. Critical aspects of using bacterial cell viability assays with the fluorophores SYTO9 and propidium iodide. BMC Microbiol. 15:36.

$\mathrm{Su}$, X., L. Guo, L. Ding, K. Qu, and C. Shen. 2016. Induction of viable but nonculturable state in Rhodococcus and transcriptome analysis using RNA-seq. PLoS One 11:e0147593.

Tawakoli, P. N., A. Al-Ahmad, W. Hoth-Hannig, M. Hannig, and C. Hannig. 2013. Comparison of different live/dead stainings for detection and quantification of adherent microorganisms in the initial oral biofilm. Clin. Oral Investig. 17:841-850.

Wright, C. T., and T. H. Klaenhammer. 1983a. Survival of Lactobacillus bulgaricus during freezing and freeze-drying after growth in the presence of calcium. J. Food Sci. 48:773-777.

Wright, C. T., and T. H. Klaenhammer. 1983b. Influence of calcium and manganese on dechaining of Lactobacillus bulgaricus. Appl. Environ. Microbiol. 46:785-792. 